\title{
Determination of the Chemical Constituent Contents and Antioxidation Properties of Asystasia Gangetica
}

\author{
Marjette YIreb Ungay Barbaza', Kathlia Aguila De Castro-Cruz¹, Chieh-Lun Hsieh², Po-Wei Tsai ${ }^{3, *}$ \\ ${ }^{1}$ School of Chemical, Biological, and Materials Engineering, and Sciences, Mapúa University, Intramuros, Manila, Metro Manila, \\ PHILIPPINES. \\ ${ }^{2}$ Educational Management Major in P.E., Graduate School, Emilio Aguinaldo College, Manila, Metro Manila, PHILIPPINES. \\ ${ }^{3}$ Department of Medical Science Industry, College of Health Sciences, Chang Jung Christian University, Tainan, TAIWAN.
}

\begin{abstract}
Background: Asystasia gangetica, also referred to as Chinese Violet is an invasive weed that has been revealed to contain biologically active components and manifest pharmacological effects. Phytochemical analysis on different extracts of $A$. gangetica reported that the plant contains steroids, sugars, phenolics, flavonoids, saponins, tannins and amino acids, alkaloids, terpenoids, quinines and carbohydrates and bioassay techniques performed using the plant material manifested its antioxidant, anti-asthmatic and antidiabetic properties. Materials and Methods: To further understand how the existing and the potential abilities of $A$. gangetica possibly work, the total phenolics, total flavonoids, total condensed tannins and total polysaccharide content of different extracts of $A$. gangetica have been analyzed as well as its antioxidation properties using DDPH and FRAP assays. The effect of combining $A$. gangetica extract to the methanolic extract of Morus alba leaves on the potency of the antioxidation properties of both plant materials was also explored. Results: Evaluation of the results revealed that $A$. gangetica ethanol extract is the extract most abundant in polyphenol, DCM extract in flavonoids and condensed tannins, while only a few extracts had polysaccharides. Ethanol extract has the most promising DPPH free radical scavenging activity, while methanol extract was reported to have the highest Trolox equivalent. No significant synergistic effect was observed in the combination of $A$. gangetica and $M$. alba extracts. Conclusion: These findings provide information on the $A$. gangetica extracts as antioxidant agents and as a source of natural products. Consequently, the results provide a new direction for medical research.
\end{abstract}

Key words: Antioxidation activity, Asystasia gangetica, Condensed tannin, Flavonoids, Polyphenol.

\section{INTRODUCTION}

The universally accepted definition of natural product is that it is a chemical compound obtained from any biological source. ${ }^{1}$ Known sources of natural substances are plants, marine life, and microorganisms, but research heavily relies on the use of plant materials. ${ }^{2}$ The exploration of traditional medicine has evolved into the study of natural products due to its ability to exhibit therapeutic effects and to its structural diversity caused by its chemical constituents. ${ }^{3}$ It is commonly claimed that natural substances have been the most productive source of active components used in the discovery and development of new medicines. In fact, drugs have been synthesized from plants that were either subjected into ethnobotany or into experiments that examined the in vitro activity against viral or cancer cell lines. ${ }^{4}$

Extraction and isolation are carried out to obtain the biologically active components that the plants possess. Plants contain both primary and secondary metabolites. Secondary metabolites are substances that do not directly affect the metabolic functions of
Submission Date: 22-10-2020; Revision Date: 02-02-2021; Accepted Date: 13-05-2021

DOI: 10.5530/ijper.55.3.160 Correspondence:

Dr. Po-Wei Tsai Department of Medical Science Industry, College of Health Sciences, Chang Jung Christian University, Tainan 711, TAIWAN. Phone no: +886-6-278-5123 Email id: powei@mail.cjcu. edu.tw

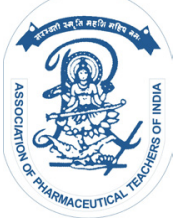

www.ijper.org 
the plant and whose purpose is more focused on defense and support. ${ }^{5}$ Many of these metabolites are found in the human diet and serve as micronutrients, which facilitate or are involved in biochemical processes. ${ }^{6}$ Polyphenols are a wide variety of molecules that have been proven to exhibit significant effects on biological processes, including metabolism and cell proliferation. This group of compounds also plays a vital role in the regulation of chronic diseases. ${ }^{7}$ Flavonoids are a class of polyphenol with low molecular weight and a wide range of derivatives. ${ }^{8}$ They are known to manifest antioxidant and anti-inflammatory properties and are also often used against bacteria and viruses. ${ }^{9}$ The biological effect of flavonoids has also been observed in the study of diabetes and cancer. Antiparasitic, antifungal, and antimicrobial activities have also been exhibited by flavonoids found in different plant materials. ${ }^{10}$ Tannins are present in different parts of a plant and serve as a protection against predators. In the past, extracted tannins were used for leather production, as adhesives, for the removal of metal ions from aqueous solutions, and other functions. ${ }^{11}$

The ability of a material to act as an antioxidant is widely studied because of the functions of antioxidants in the body. Oxidation is a natural reaction in the body, but an imbalance between the supply of reactive oxygen species (ROS) and free radicals and the availability of antioxidants lead to the development of oxidative stress, leading to damaged tissues and cells. ${ }^{12}$ Studies have also linked oxidative damage to the development of several diseases, including cancer. ${ }^{13}$ Because of this, many studies have focused on finding natural sources of antioxidants. Asystasia gangetica, also referred to as Chinese Violet, ${ }^{14}$ is a weed that produces large quantity of seeds and easily germinates, causing it to be considered an invasive weed. Despite its invasive nature, A. gangetica has been used as a cover crop and has been found to help in pest control because of the ability of its flowers and trichome to attract parasitoid caterpillar bag, consequently protecting the valuable crops. Aside from these uses, A. gangetica has been revealed to exhibit biological properties which it owes to its active components. ${ }^{15,16}$ Chemical constituent analyses have also been performed on the extracts Asystasia gangetica and on other species of the Asystasia genus. Phytochemical analysis on different extracts of $A$. gangetica as presented by Janakiraman $e t$ al. showed that the plant contains steroids, sugars, phenolics, flavonoids, saponins, tannins, and amino acids. ${ }^{17}$ In another phytochemical screening done on the same year using $A$. gangetica hexane, chloroform, ethyl acetate, $\mathrm{EtOH}$, and water extracts also revealed the presence of alkaloids, terpenoids, quinines, and carbohydrates. ${ }^{18}$
To know whether a plant material is a candidate for the discovery of new drugs, the analysis of its constituents is one of primary steps that must be done.

Aside from its' bioactive components, the pharmacological activities of $A$. gangetica have also been explored in some studies. It has been reported that the medicinal plant exhibits antioxidant, anti-asthmatic, and antidiabetic properties. ${ }^{19-23}$ Another plant material, Morus alba, has also been reported to exhibit activities similar to that of $A$. gangetica. ${ }^{24}$ To further understand how the existing and the potential abilities of $A$. gangetica possibly work, this study aims to obtain crude extracts of $A$. gangetica from different solvents via reflux extraction and perform chemical constituent analyses on $A$. gangetica extracts to determine the total phenolics, total flavonoids, total condensed tannins, and total polysaccharide content. This also allows the assessment of the biologically active components that the plant material possesses and gives an understanding as to why it manifests biological activities that have been observed and reported by other studies. The antioxidation properties of $A$. gangetica and the synergistic effect of its combination with $M$. alba methanolic extract are to be examined as well through antioxidation assays.

\section{MATERIALS AND METHODS}

\section{Materials and Equipment}

Asystasia gangetica whole plants were collected on September 2, 2019 in Chang Jung Christian University, Tainan, Taiwan. Dried leaves of Morus alba was purchased from a local herbal store. The identities of both plants were authenticated by Dr. Chia-Jung Lee, Ph.D. Program in Clinical Drug Development of Herbal Medicine, College of Pharmacy, Taipei Medical University. Voucher specimens were deposited as \#CJCU-AG-001 and \#CJCU-MA-001 for A. gangetica and M. alba, respectively, at the Department of Medical Sciences Industry in Chang Jung Christian University, Taiwan. All chemical reagents used in the experiments were bought from Sigma-Aldrich.

\section{Sample Preparation and Extraction}

A. gangetica whole plants were oven-dried at $40^{\circ} \mathrm{C}$ and were powdered using a blender after three days. Six replicates of $50 \mathrm{~g}$ of ground $A$. gangetica were weighed and extracted through reflux using six different solvents which are, $\mathrm{MeOH}, \mathrm{EtOH}$, acetone, EA, DCM, and hexane $\left(12-\mathrm{hr}, 65^{\circ} \mathrm{C}, 1 \mathrm{~L}\right)$, while $M$. alba leaves were extracted using $50 \% \mathrm{MeOH}$ in water. ${ }^{24}$ Another $50 \mathrm{~g}$ of ground $A$. gangetica was subjected to decoction using 4 $\mathrm{L}$ of $\mathrm{DD} \mathrm{H}_{2} \mathrm{O}$ to obtain an aqueous extract. The crude 
extracts were collected via vacuum filtration and the solvents were removed from the filtrate using a rotary evaporation in preparation for the freeze-drying. The $A$. gangetica samples were then prepared in a microcentrifuge tube by dissolving $10 \mathrm{mg}$ of each of the dried extracts in $1 \mathrm{~mL}$ of ethanol, except for the aqueous extract, which was prepared using distilled and deionized water. The combined $A$. gangetica and $M$. alba extracts were prepared by mixing $50 \% \mathrm{MeOH} M$. alba extract (MA) dissolved in EtOH $(10 \mathrm{mg} / \mathrm{ml})$ to the previously prepared $A$. gangetica EtOH extract (AG) with 0 to 100 percent volume to afford a total of 11 solutions, which are 100\% AG, 90\% AG-10\% MA, 80\% AG-20\% MA, 70\% AG-30\% MA, 60\% AG-40\% MA, 50\% AG-50\% MA, 40\% AG-60\% MA, 30\% AG-70\% MA, 20\% AG-80\% MA, 10\% AG-90\% MA, and 100\% MA. All samples were then stored at a temperature not higher than $-20^{\circ} \mathrm{C}$.

\section{Total Polyphenol Content Analysis}

Analysis of the total polyphenol content present in the extracts was done following the method of Singleton. ${ }^{25}$ Freshly prepared gallic acid stock solution $(1 \mathrm{mg} / \mathrm{mL})$ was utilized to prepare five standard solutions to afford a range of concentration from 0.50000 to $0.03125 \mathrm{mg} /$ $\mathrm{ml}$, while $100 \mu \mathrm{L}$ of the initially prepared sample extracts were diluted with $1 \mathrm{~mL}$ of EtOH for all extracts except aqueous, which was diluted with $1 \mathrm{~mL}$ of water, to give a concentration of $1 \mathrm{mg} / \mathrm{mL}$. A volume of $100 \mu \mathrm{L}$ of the standard solutions and the diluted extracts were reacted with $500 \mu \mathrm{L}$ of Folin-Ciocalteu reagent and $20 \%$ solution for $35 \mathrm{~min}$ and at room temperature. Afterwards, $200 \mu \mathrm{L}$ of the reaction mixtures was transferred in a 96-well plate in triplicates and the absorption was read at $600 \mathrm{~nm}$. The total polyphenol content was obtained based on the calibration curve formed by the standard solutions of gallic acid.

\section{Total Flavonoid Content Analysis}

The aluminum trichloride method presented in the study of Rebaya et al. (2014) ${ }^{26}$ was modified to assess the total flavonoid content of $A$. gangetica. The standard compound rutin was subjected to a serial dilution to obtain five concentrations $(0.40,0.20,0.10,0.05,0.025$ $\mathrm{mg} / \mathrm{ml}$ ) while $A$. gangetica sample extracts were prepared to afford a concentration of $1 \mathrm{mg} / \mathrm{ml}$. For the reaction, $500 \mu \mathrm{L}$ of each of the solutions was mixed with $2 \% \mathrm{AlCl}_{3}$ in $\mathrm{MeOH}$ at room temperature and was set aside for $15 \mathrm{~min}$. The absorption was determined with a 96-well plate containing $200 \mu \mathrm{L}$ of each solution in triplicates.

\section{Total Condensed Tannin Content Analysis}

For the analysis of the total condensed tannin present in A. gangetica extracts, $5 \mathrm{mg}$ of catechin was dissolved in
$1 \mathrm{~mL}$ of EtOH and was diluted to obtain five standard solutions $(0.16,0.08,0.04,0.02,0.01 \mathrm{mg} / \mathrm{ml})$, while $100 \mu \mathrm{L}$ of the sample extracts $(10 \mathrm{mg} / \mathrm{ml})$ were diluted with 300 $\mu \mathrm{L}$ of $\mathrm{EtOH}$. Then, $300 \mu \mathrm{L}$ of each standard solution and sample solutions were allowed to react with 600 $\mu \mathrm{L}$ of vanillin in $\mathrm{H}_{2} \mathrm{SO}_{4}$, prepared by mixing $0.1 \mathrm{~g}$ of vanillin with $10 \mathrm{ml}$ of $80 \% \mathrm{H}_{2} \mathrm{SO}_{4}$, at room temperature for $15 \mathrm{~min}$. Three replicates of $200 \mu \mathrm{L}$ of the solution were transferred in a 96-well plate for the measurement of absorbances at $530 \mathrm{~nm}$.

\section{Total Polysaccharide Content Analysis}

A procedure similar to that of Cirillo et al. ${ }^{27}$ was used to determine the total polysaccharide content of $A$. gangetica extracts. A standardized curve was obtained by allowing different volumes of glucose (50, 40, 30, 20, 10, $5 \mu \mathrm{L}$ ) from a glucose stock solution with a concentration of $0.01 \mathrm{mg} / \mathrm{ml}$ to react with $1 \mathrm{~mL}$ of $\mathrm{DD} \mathrm{H}_{2} \mathrm{O}, 0.5$ $\mathrm{ml}$ of $5 \%$ phenol solution, and $5 \mathrm{ml}$ of concentrated $\mathrm{H}_{2} \mathrm{SO}_{4}$ in a regular test tube for $15 \mathrm{~min}$ in a boiling water bath. The solutions were cooled down and 200 $\mu \mathrm{L}$ of each were transferred into a 96-well in triplicates. Absorbance's were read at $485 \mathrm{~nm}$. For the $A$. gangetica extracts, the extraction of the polysaccharides was done by refrigerating $125 \mu \mathrm{L}$ of the previously prepared sample solutions $(10 \mathrm{mg} / \mathrm{ml})$ diluted in $1 \mathrm{~mL}$ of $95 \% \mathrm{EtOH}$ for a day. Afterwards, the solutions were centrifugated $\left(10^{\circ} \mathrm{C}, 1300 \mathrm{rpm}, 10 \mathrm{~min}\right)$ and the polysaccharide extract separated from the supernatant liquid was washed by $80 \% \mathrm{EtOH}$ for another $30 \mathrm{~min}$. The washed extracts were centrifugated at the same conditions and the washing was removed. The polysaccharide extracts were reacted with the same chemicals added to the glucose standard solutions and the same steps were performed.

\section{DPPH Free Radical Scavenging Assay}

In performing the DPPH assay, $200 \mu \mathrm{M}$ of 1,1-diphenyl$\beta$-picryl hydrazine (DPPH) solution was first prepared by mixing $9.863 \mathrm{mg}$ of DPPH with $50 \mathrm{~mL}$ ethanol with minimum exposure to light. The standard compound ascorbic acid $(5 \mathrm{mg} / \mathrm{ml})$ was serially diluted to obtain six concentrations $(0.5000$ to $0.0078 \mathrm{mg} / \mathrm{ml}$ ) while the A. gangetica extracts, the M. alba methanolic extract, and the combined extracts of both plants were diluted to obtain a concentration range from 2.500 to $0.1563 \mathrm{mg} /$ $\mathrm{ml}$. A volume of $50 \mu \mathrm{L}$ of each standard and samples solution was transferred in triplicates in a 96-well plate and was incubated upon the addition of $150 \mu \mathrm{L}$ of the fresh DPPH solution for 30 min on a shaker without light exposure. Absorbances were later read at $517 \mathrm{~nm}$ 
and the percent inhibition were calculated using the following equation:

$$
\% \text { inhibition }=\frac{\mathrm{Abs}_{\text {control }}-\mathrm{Abs}_{\text {sample }}}{A b s_{\text {control }}} \times 100 \%
$$

and the final results were expressed in the half-maximal inhibitory concentration $\left(\mathrm{IC}_{50}\right)$.

\section{Ferric Reducing Ability Power Assay}

The reaction reagent containing $300 \mathrm{mM}$ of sodium acetate buffer solution, $5 \mathrm{mM}$ of 2,4,6-tris(2-pyridyl)-striazine (TPTZ) solution, and $20 \mathrm{mM}$ of ferric chloride hexahydrate solution was prepared in a 10:1:1 ratio. The standard was prepared by diluting a solution of $10 \mathrm{mg}$ of Trolox in $2 \mathrm{~mL} \mathrm{EtOH}$ and $3 \mathrm{~mL}$ with EtOH to afford seven different concentrations from 1.000 to 0.0078 $\mathrm{mg} / \mathrm{ml}$. A mixture of $50 \mu \mathrm{L}$ of the standard solutions and $1450 \mu \mathrm{L}$ of the reaction reagent was reacted in a microcentrifuge tube for approximately $5 \mathrm{~min}$, before $200 \mu \mathrm{L}$ of the mixture was transferred in a 96-well plate in triplicates. The absorbances were measured at $593 \mathrm{~nm}$ and the results were recorded as the mg of Trolox per mg of extract.

\section{RESULTS}

\section{Chemical Constituents of $\boldsymbol{A}$. gangetica}

The total polyphenol, total flavonoids, total condensed tannins, and total polysaccharide contents of $A$. gangetica

\begin{tabular}{|c|c|c|c|c|}
\hline 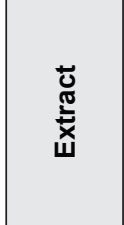 & $\begin{array}{l}\overline{0} \\
\frac{0}{0} \\
\frac{0}{0} \\
\frac{0}{2} \\
\frac{0}{0}\end{array}$ & $\begin{array}{l}\frac{0}{0} \\
\frac{0}{0} \\
\frac{\pi}{0} \\
\frac{\pi}{4}\end{array}$ & 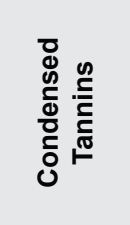 & 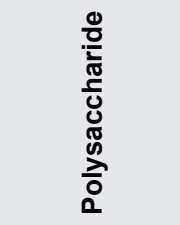 \\
\hline & $\begin{array}{c}73.794 \pm \\
2.680\end{array}$ & $\begin{array}{c}10.960 \pm \\
0.082\end{array}$ & $\begin{array}{c}11.870 \pm \\
0.405\end{array}$ & $9.929 \pm 0.108$ \\
\hline $\mathrm{MeOH}$ & $\begin{array}{c}104.868 \pm \\
4.485\end{array}$ & $\begin{array}{c}85.483 \pm \\
0.297\end{array}$ & $\begin{array}{c}36.250 \pm \\
1.565\end{array}$ & $0.257 \pm 0.016$ \\
\hline $\mathrm{EtOH}$ & $\begin{array}{c}273.901 \pm \\
1.598\end{array}$ & $\begin{array}{c}189.900 \pm \\
0.622\end{array}$ & $\begin{array}{c}49.958 \pm \\
2.498\end{array}$ & $0.155 \pm 0.008$ \\
\hline Acetone & $\begin{array}{c}231.768 \pm \\
2.678\end{array}$ & $\begin{array}{c}419.428 \pm \\
1.927\end{array}$ & $\begin{array}{c}71.942 \pm \\
0.616\end{array}$ & N.D. \\
\hline EA & $\begin{array}{c}168.665 \pm \\
2.005\end{array}$ & $\begin{array}{c}421.569 \pm \\
0.297\end{array}$ & $\begin{array}{c}68.661 \pm \\
0.856\end{array}$ & N.D. \\
\hline DCM & $\begin{array}{c}107.580 \pm \\
3.206\end{array}$ & $\begin{array}{c}419.428 \pm \\
0.795\end{array}$ & $\begin{array}{c}91.745 \pm \\
1.922\end{array}$ & N.D. \\
\hline Hexane & $\begin{array}{c}101.405 \pm \\
1.630\end{array}$ & $\begin{array}{c}201.555 \pm \\
0.540\end{array}$ & $\begin{array}{c}43.494 \pm \\
0.698\end{array}$ & N.D. \\
\hline
\end{tabular}

*N.D. $=$ not detected

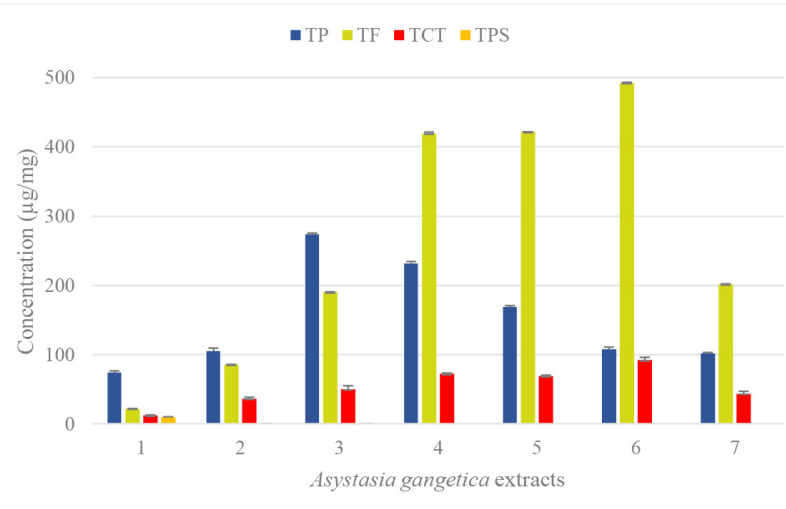

Figure 1: Chemical constituents of $\boldsymbol{A}$. gangetica extracts. *1 - aqueous extract; 2 - MeOH extract; 3 - EtOH extract; 4 - acetone extract; 5 - EA extract; 6 - DCM extract; 7 - hexane extract

extracts are presented in Table 1 and a visual comparison between the extracts is provided in Figure 1. All components are expressed in microgram per milligram of extract.

\section{Total Polyphenol Content}

Evaluation of the absorbances of gallic acid from 5 to $0.03125 \mathrm{mg} / \mathrm{ml}$ resulted in a standard curve with the linear equation $y=0.0051 \mathrm{x}-0.1753$ corresponding to absorbance $=\mathrm{m}$ (polyphenol content $)+\mathrm{b}$ with a coefficient of determination $\left(R^{2}\right)$ equal to 0.9926 . Given the absorbances of the A. gangetica extracts subjected into the Folin-Ciocalteu method, the total polyphenol content of each extract was determined. Ethanol extract was revealed to have the most abundant polyphenol content among the $A$. gangetica extracts with $273.901 \pm$ $1.598 \mu \mathrm{g} / \mathrm{mg}$ extract, followed by the acetone extract with $231.768 \pm 2.678 \mu \mathrm{g} / \mathrm{mg}$.

\section{Total Flavonoid Content}

Using rutin as the standard compound resulted in a calibration curve $y=0.007 \mathrm{x}+0.0469$ based on the linear equation absorbance $=\mathrm{m}($ flavonoid content $)+\mathrm{b}$ with $\mathrm{R}^{2}$ equal to 0.9966 . Quantification of the total flavonoids present in $A$. gangetica extracts was done using this curve and the findings show that DCM extract contains the highest amount of flavonoids and that less or non-polar A. gangetica extracts are generally more abundant in terms of flavonoid content.

\section{Total Polysaccharide Content}

Determination of the total polysaccharide content using glucose standard with concentrations ranging from 0.005 to $0.0005 \mathrm{mg} / \mathrm{ml}$ gave the calibration curve of $\mathrm{y}$ $=0.0579 \mathrm{x}+0.0148$ with a coefficient of determination equal to 0.9885 . The polysaccharide concentration present in the extracts were calculated using the curve and 
only the aqueous, methanol, and ethanol extracts were found to contain detectable amount of polysaccharide at a concentration of $10 \mathrm{mg} / \mathrm{ml}$. No polysaccharide was detected from the rest of the extracts even at a concentration of $20 \mathrm{mg} / \mathrm{ml}$ and the solubility of the extract to EtOH prevented the use of an even higher concentration.

\section{Total Condensed Tannins Content}

The analysis of the total condensed tannins possessed by $A$. gangetica sample extracts were obtained by forming the standard curve using the absorption of catechin at different concentrations (10 to $160 \mathrm{ug} / \mathrm{mL}$ ). The linear equation used was $\mathrm{y}=0.0122 \mathrm{x}+0.062$ with an $\mathrm{R}^{2}$ value of 0.9995 . The DCM extract has the highest concentration of condensed tannins among the $A$. gangetica extracts, but it can be observed that amount of condensed tannins is relatively low compared to that of polyphenols and flavonoids. Aside from this, the

\begin{tabular}{|c|c|c|}
\hline \multicolumn{2}{|c|}{ Table 2: Antioxidant activities of A. gangetica } \\
extracts. \\
\hline Extract & $\begin{array}{c}\text { DPPH assay } \\
\text { (mg/ml) }\end{array}$ & $\begin{array}{c}\text { FRAP assay } \\
\text { mg Trolox/mg } \\
\text { extract }\end{array}$ \\
\hline & N.D. & $0.016 \pm 0.000$ \\
\hline $\mathrm{MeOH}$ & $1.75 \pm 0.021$ & $0.080 \pm 0.002$ \\
\hline EtOH & $1.28 \pm 0.008$ & $0.069 \pm 0.002$ \\
\hline Acetone & $4.22 \pm 0.067$ & $0.064 \pm 0.000$ \\
\hline EA & N.D. & $0.036 \pm 0.000$ \\
\hline DCM & N.D. & $0.033 \pm 0.000$ \\
\hline Hexane & N.D. & $0.018 \pm 0.000$ \\
\hline Ascorbic acid & $1.24 \pm 0.040$ & - \\
\hline
\end{tabular}

*N.D. = not detected

\begin{tabular}{|c|c|c|c|}
\hline \multicolumn{4}{|c|}{$\begin{array}{c}\text { Table 3: Antioxidant activities of combined } \\
\text { A. gangetica ethanolic extract and } M . \text { alba 50\% } \\
\text { methanolic extract. }\end{array}$} \\
$\begin{array}{c}\text { \%v/v of } \\
\begin{array}{c}\text { A.gangetica } \\
\text { extract (\%v/v) }\end{array}\end{array}$ & $\begin{array}{c}\text { \% v/v of } \\
\text { M. alba } \\
\text { extract }\end{array}$ & $\begin{array}{c}\text { DPPH assay } \\
\text { IC }_{50} \text { (mg/ml) }\end{array}$ & $\begin{array}{c}\text { FRAP assay } \\
\text { mg trolox/ } \\
\text { mg extract }\end{array}$ \\
\hline 100 & & $1.28 \pm 0.008$ & $0.069 \pm 0.002$ \\
\hline 90 & 10 & $1.45 \pm 0.029$ & $0.069 \pm 0.001$ \\
\hline 80 & 20 & $0.98 \pm 0.039$ & $0.073 \pm 0.001$ \\
\hline 70 & 30 & $1.43 \pm 0.019$ & $0.069 \pm 0.001$ \\
\hline 60 & 40 & $1.40 \pm 0.015$ & $0.071 \pm 0.001$ \\
\hline 50 & 50 & $1.31 \pm 0.037$ & $0.064 \pm 0.000$ \\
\hline 40 & 60 & $1.29 \pm 0.022$ & $0.073 \pm 0.001$ \\
\hline 30 & 70 & $1.12 \pm 0.019$ & $0.071 \pm 0.001$ \\
\hline 20 & 80 & $1.09 \pm 0.030$ & $0.075 \pm 0.001$ \\
\hline 10 & 90 & $1.09 \pm 0.052$ & $0.076 \pm 0.000$ \\
\hline 0 & 100 & $1.11 \pm 0.034$ & $0.075 \pm 0.001$ \\
\hline
\end{tabular}

chemical constituent is more abundantly present in nonpolar extracts than in polar ones.

\section{Antioxidant activities of $A$. gangetica extracts}

To assess the antioxidation abilities of $A$. gangetica extracts and the effect on its potency in combination with the methanolic extract of $M$. alba, both DPPH

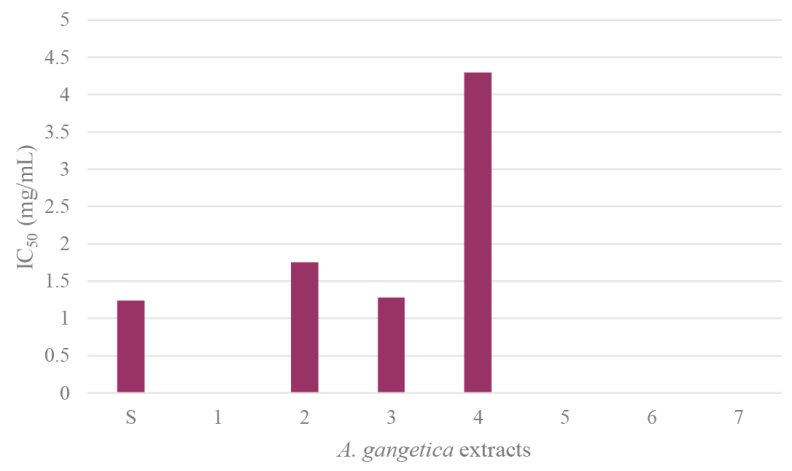

Figure 2: Antioxidant activities of $\boldsymbol{A}$. gangetica extracts (DPPH assay).

*S - ascorbic acid; 1 - aqueous extract; 2 - MeOH extract; 3 - EtOH extract; 4 acetone extract; 5 -EA extract; 6 - DCM extract; 7 - hexane extract

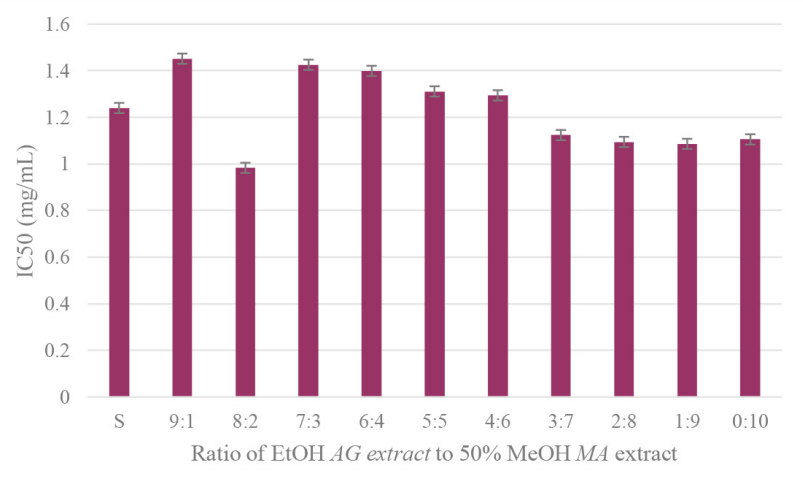

Figure 3: Antioxidant activities of combined AG and MA extracts (DPPH assay).

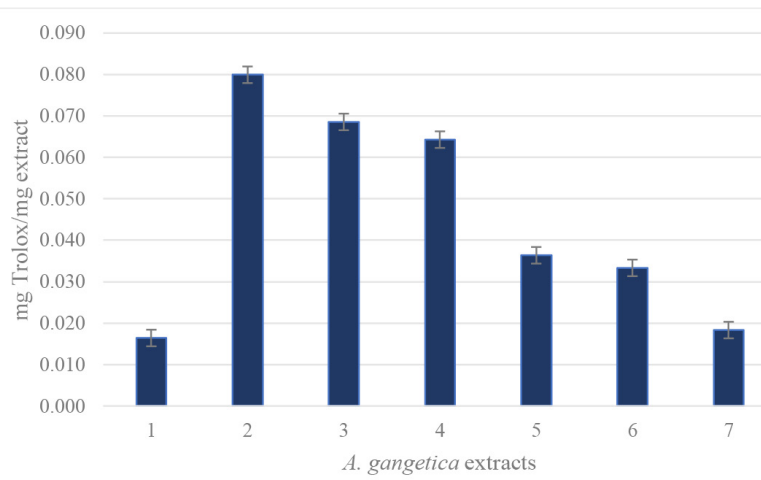

Figure 4: Antioxidant activities of $\boldsymbol{A}$. gangetica extracts (DPPH assay).

*S - ascorbic acid; 1 - aqueous extract; 2 - MeOH extract; 3 - EtOH extract; 4 acetone extract; 5 - EA extract; 6 - DCM extract; 7 - hexane extract 


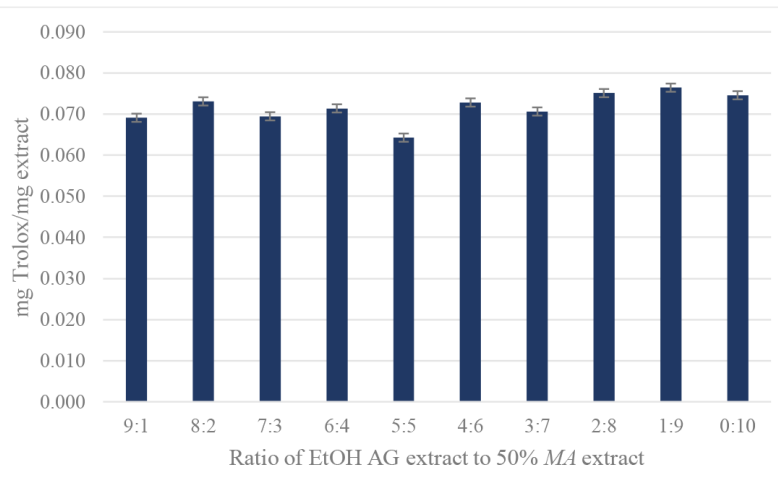

Figure 5: Antioxidant activities of combined AG and MA extracts (FRAP assay).

free radical scavenging assay and ferric reducing ability power assay (FRAP) assay were carried out. The data gathered for both assays are displayed in Tables 2 and 3, wherein the results are expressed as the $\mathrm{IC}_{50}$ and the $\mathrm{mg}$ Trolox equivalent per mg extract for DPPH assay and FRAP assay, respectively. Figures corresponding to the tabulated data are also presented and labelled as Figures $2-5$.

\section{DPPH Free Radical Scavenging Activity}

The positive results were visually observed when the solutions turned from a purple color into a yellow one after the period of incubation. The $\mathrm{IC}_{50}$ of $A$. gangetica extracts presented in Table 2 shows that only methanol, ethanol, and acetone extracts manifest antioxidation activity against DPPH free radicals, with ethanol being the most promising among the extracts with an $\mathrm{IC}_{50}$ of $1.28 \pm 0.008 \mathrm{mg} / \mathrm{ml}$. This is also not too far from the $\mathrm{IC}_{50}$ of the standard compound, ascorbic acid, which was $1.24 \pm 0.040 \mathrm{mg} / \mathrm{ml}$. Because of these findings, ethanol extract was used to explore the synergistic effect it may have with the $50 \%$ methanol extract of M. alba, which results are shown in Table 3. No major differences were observed in varying the ratio of the volume of both extracts and $\mathrm{IC}_{50}$ 's lower than that of the standard were calculated at higher volume percentages of $M$. alba extract, except for the most favorable result with an $\mathrm{IC}_{50}$ of $0.98 \pm 0.039 \mathrm{mg} / \mathrm{ml}$ at $80 \%$ A. gangetica ethanol extract.

\section{Ferric Reducing Ability Power Activity}

The reducing power was observed with a color change into blue. Trolox was used as the standard and a calibration curve of $\mathrm{y}=3.5311 \mathrm{x}+0.102$ with an $\mathrm{R}^{2}$ of 0.9999 was utilized to obtain the Trolox equivalents present in the extracts. Table 2 shows a trend of decreasing Trolox equivalent in $A$. gangetica extracts as the solvent extract becomes less polar, except for the aqueous extract, which has a relatively low Trolox equivalent. The combined extracts of $A$. gangetica and $M$. alba did not have any significant effect to the FRAP activity of the extracts and similar to the results in DPPH assay, the Trolox equivalents are found to be higher at higher volume percentages of $M$. alba extract, except for the result at $80 \%$ A. gangetica ethanol extract, which has a Trolox equivalent of $0.073 \mathrm{mg} / \mathrm{mg}$ extract.

\section{DISCUSSION}

Polyphenols are a wide variety of molecules that have been proven to exhibit significant effects on biological processes, including metabolism and oxidation, and are present in a wide variety of plant species. This group of compounds is composed of phenol rings and hydroxyl groups that allow it to play a vital role in the regulation of chronic diseases. Flavonoids are a class of polyphenol with low molecular weight and a wide range of derivatives, which enable them to act as antioxidant and anti-inflammatory agents. ${ }^{17}$ Results of this study revealing that $A$. gangetica extracts are abundant in both chemical constituents, as shown in Table 1, open up the possibility of the extracts exhibiting promising pharmacological applications, including antioxidation. Condensed tannins, also referred to as proanthocyanidins, are also compounds that have been studied for its antioxidation effects. Although the $A$. gangetica extracts are not as rich in condensed tannins as they are in the aforementioned groups of compounds, it is still significant to know that condensed tannins are present and may still have an impact on the activities manifested by the samples.

Lastly, some polysaccharides are also bioactive components that contribute to the pharmacological applications of plant sources. In line with this, the polysaccharide content of the extracts has also been examined. However, the data obtained showed that only three extracts have detectable polysaccharide content and given its concentration and the antioxidation activities of the extracts, it is less likely that the polysaccharides present in the samples were able to contribute in this specific pharmacological activity being explored in the study. It is possible that the extracts contain polysaccharides that are untraceable with the technique performed.

As mentioned, an imbalance between the oxidants and antioxidants in the body causes oxidative stress, and leads to damaged tissues and cells. This means that oxidative damage may results to several complications and diseases. This is why excessive oxidation is one of the most widely studied cause of a disease and why the antioxidation activity of a natural product is one of the 
primary properties explored many studies. ${ }^{12,13} \mathrm{DPPH}$ is a free radical that is used in determining the free radicalscavenging ability of samples. In DPPH assay, DPPH is inhibited by the antioxidants present in a sample, consequently turning the solution from a purple color into a yellow one. It can be observed that extracts with polar to semi-polar solvents and with high polyphenol content were able to exhibit the free radical scavenging activity. This is consistent with the claim that polyphenols contribute in antioxidation. Aside from scavenging of DPPH free radicals, the reducing power of $\mathrm{Fe}^{2+}$ by $A$. gangetica extracts is evaluated using the ferric reducing ability of plasma or FRAP assay. Although both are utilized to assess the antioxidation property of a material, the two differ in mechanisms. The ability of an extract to inhibit free DPPH radicals as a manifestation of its antioxidant property may not be as potent as its action in FRAP assay, and vice versa. In FRAP assay, the ability of a component to transform a complex from $\mathrm{Fe}^{3+}$ to $\mathrm{Fe}^{2+}$ form and the solution changing from its original color into either green or blue solution indicate the manifestation of the antioxidation property of a material. It can be seen that the Trolox equivalent in each extract is inversely proportional to the polarity of the solvent used in the extract. It can also be observed that although nonpolar extracts, specifically EA, DCM, and hexane extracts are not active in DPPH assay, their antioxidant activities were recorded in FRAP assay. This variation may be caused by the difference in mechanisms in which the antioxidation occurs. Aside from these findings, it is also clear that the combination of $A$. gangetica extracts and $M$. alba methanolic extract did not produce a synergistic effect to significantly enhance the antioxidation activity of the extracts.

A. gangetica is not as widely studied as other plant materials, but most of existing literature studies on this plant were focused on either ethanol or methanol extraction. The results of this study are also consistent with them. As previously mentioned, the chemical constituents which are abundant in these extracts, such as polyphenols and flavonoids, largely contribute to their potential to be applied pharmacologically. Further investigation on these extracts is definitely recommended. However, it is also important to note that there are only two biological assays presented in this paper and generally, few have been explored using $A$. gangetica extracts as subjects. Therefore, what is presented may not be enough to conclude the overall potential of the other A. gangetica extracts. Further studies on all extracts may be considered.

\section{CONCLUSION}

In conclusion, $A$. gangetica extracts indeed contains biologically active compounds that contribute to its pharmacological activities, with ethanol and DCM extracts being the most abundant in polyphenols and flavonoids, respectively. The polar and semi-polar extracts also manifested their ability to scavenge free radicals through DPPH assay, while all extracts were able to exhibit their reducing power ability in a polaritydependent manner as well. Although both $A$. gangetica ethanolic extract and $M$. alba methanolic extract have manifested antioxidation activities, the combination of both extracts did not affect the half-maximal inhibitory concentration value essentially. Overall, these findings provide information on the $A$. gangetica extracts as antioxidant agents and as a source of natural products. Consequently, the results provide a new direction for medical research.

\section{ACKNOWLEDGEMENT}

The authors are thankful to Office of Research and Development, Chang Jung Christian University, for funding this project.

\section{Author Contribution}

Conceptualization, M.Y.U.B and P.-W.T.; methodology, formal analysis and data curation, M.Y.U.B, C.L.H., K.A.D.C.-C. and P.-W.T.; writing-original draft preparation, M.Y.U.B; supervision, K.A.D.C.-C. and P.-W.T.. All authors read and approved the final manuscript.

\section{CONFLICT OF INTEREST}

The authors declare that there is no conflict of interests regarding the publication of this article.

\section{ABBREVIATIONS}

DPPH: 1,1-diphenyl- $\beta$-picryl hydrazine; $\boldsymbol{A}$. gangetic: Asystasia gangetic, M. alba: Morus alba; FRAP: ferric reducing ability power activity; EA: ethyl acetate; DCM: dichloromethane.

\section{REFERENCES}

1. All natural. Nat Chem Biol. 2007;3:351. Available from: http://doi.org/10.1038/ nchembio0707-351.

2. Rasul MG. Extraction, isolation and characterization of natural products from medicinal plants. Int J Basic Sci Appl Computing. 2018;2:1-6.

3. Harvey AL. Natural products in drug discovery. Drug Discov Today. 2008;13(19-20):894-901. 
4. Kulka M. Using old solutions to new problems: natural drug discovery in the $21^{\text {st }}$ Century. Croatia: In Tech. 2013.

5. Heldt HW. Plant Biochemistry, $3^{\text {rd }}$ ed. Academic Press. 2005.

6. Williamson $G$. The role of polyphenols in modern nutrition. Nutr Bull. 2017;42(3):226-35.

7. Cory H, Passarelli S, Szeto J, Tamez M, Mattei J. The role of polyphenols in human health and food systems: A mini-review. Front Nutr. 2018;5:87.

8. Wang TY, Li Q, Bi KS. Bioactive flavonoids in medicinal plants: Structure, activity and biological fate. Asian J Pharm Sci. 2018;13(1):12-23.

9. Karak P. Biological activities of flavonoids: An overview. Int J Pharm Sci Res. 2019;10(4):1567-74.

10. Jucá MM, Filho FMSC, DeAlmeida JC, Mesquita DD, Barriga JRD, Dias KCF. Flavonoids: Biological activities and therapeutic potential. Nat Prod Res. 2020;34(5):692-705.

11. Wina E, Susana IWR, Tangendjaja B. Biological activity of tannins from Acacia mangium bark extracted by different solvents. Media Peternakan. 2010;33(2):103-7.

12. Reuter S, Gupta SC, Chaturvedi MM, Aggrwal BB. Oxidative stress, inflammation, and cancer: How are they linked?. Free Radical Bio Med. 2010;49(1):1603-16.

13. Oberley TD. Oxidative damage and cancer. Am J Pathol. 2002;160(2):403-8.

14. Gopal TK, Megha G, Chamundeeswari D, Reddy CU. Phytochemical and pharmacological studies on whole plant of Asystasia gangetica. Indian J Res Pharm Biotech. 2013;1(3):365.

15. Ariyanti M, Mubarok S, Asbur Y. Study of Asystasia gangetica (L.) T. Anderson as cover crop against soil water content in mature palm oil plantation. $J$ Agronomy. 2017;16(4):154-9.

16. Asbur $\mathrm{Y}$, Purwaningrum $\mathrm{Y}$, Ariyanti $\mathrm{M}$. Growth and nutrient balance of Asystasia gangetica (L.) T. Anderson as cover crop for mature oil palm (Elaeis guineensis Jacq.) plantations. Chilean J Agric Res. 2018;78(4):486-94.
17. Janakiraman $\mathrm{N}$, Jasmin JJ, Johnson $\mathrm{M}$, Jeeva S, Renisheya JJMT. Phytochemical analysis on Asystasia gangetica (L.) T. Anderson. Jour Harmo Res Pharm. 2012;1:19-32.

18. Sama K, Sivaraj R, Salam HA, Rajiv P. Pharmacognostical and phytochemical screening of Asystasia gangetica. Intl Res J Pharm. 2013;4(2):161-3.

19. Reddy NVLS, Anarthe SJ, Raghavendra NM. Evaluation of in-vitro antioxidant activity of methanol extract of Asystasia gangetica (L).T (Chinese violet). Natural Products: An Indian Journal. 2009;5:78-80.

20. Reddy NVLS, Anarthe SJ, Raghavendra NM. In vitro antioxidant and antidiabetic activity of Asystasia gangetica (Chinese Violet) Linn. (Acanthaceae). Int J Res Pharm Biomed Sci. 2010;1(2):72-5.

21. Sama K, Sivaraj R, Rajiv P. In vitro antidiabetic activity of anthocyanin of Asystasia gangetica. Intl Res J Pharm. 2013;3(2):88-92.

22. Kumar RP, Sujatha D, Saleem TSM, Chetty CM, Ranganayakulu D. Potential antidiabetic and antioxidant activities of Morus indica and Asystasia gangetica in allocxan-induced diabetes mellitus. J Exp Pharmacol. 2010;2:29-36.

23. Akah PA, Ezike AC, Nwafor SV, Okoli CO, Enwerem NM. Evaluation of the antiasthmatic property of Asystasia gangetica leaf extracts. J Ethnopharmacol. 2003;89(1):25-36.

24. Ganzon JG, Chen LG, Wang CC. 4-O-Caffeoylquinic acid as antioxidant marker for mulberry leaves rich in phenolic compounds. J Food Drug Anal. 2017;26(3):985-93.

25. Singleton V, Rossi J. Colorimetry of total phenolics with phosphomolibdicphosphotungstic acid reagents. Am J Enol Vitic. 1965;16(3):144-58.

26. Rebaya A, Belghith SI, Baghdikian B, Leddet VM, Mabrouki F, Olivier E, et al. Total phenolic, total flavonoid, tannin content, and antioxidant capacity of Halimium halimifolium (Cistaceae). J Appl Pharm Sci. 2014;5(1):52-7.

27. Cirillo VP, Wilkins PO, Anton J. Sugar transport in a psychrophilic yeast. Journal of Bacteriology. 1963;86(6):1259-64.

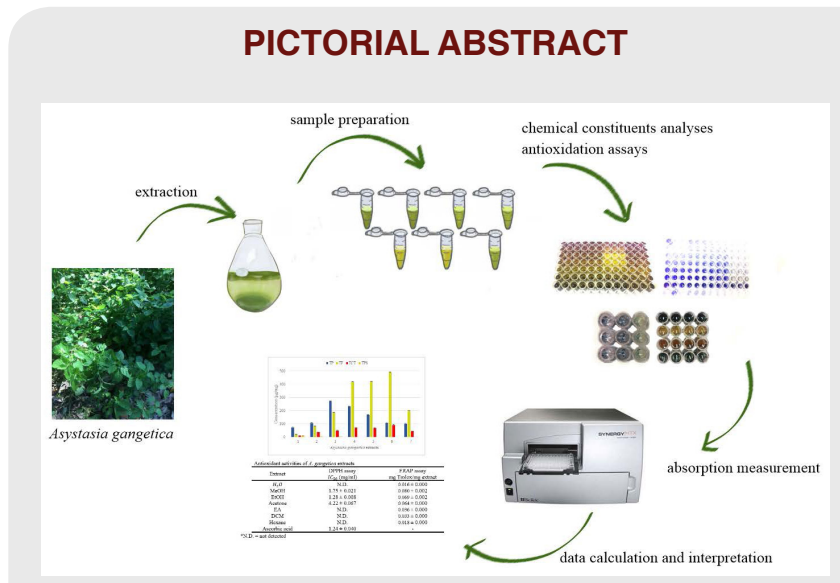

\section{SUMMARY}

Asystasia gangetica, also referred to as Chinese Violet, is an invasive weed that has been revealed to contain biologically active components and manifest pharmacological effects such as antioxidant, antiasthmatic and antidiabetic activites. To further understand how the existing and the potential abilities of $A$. gangetica possibly work, the total phenolics, total flavonoids, total condensed tannins and total polysaccharide content of different extracts of $A$. gangetica have been analyzed as well as its antioxidation properties using DDPH and FRAP assays. Its ability to exhibit synergism has also been observed by combining the extracts with $50 \% \mathrm{MeOH}$ extract of Morus alba, another plant material found to have an antioxidation activity. 


\section{About Authors}

Marjette Ylreb Ungay Barbaza is a recent Graduate of Bachelor of Science in Chemical Engineering, Bachelor of Science in Chemistry, and Master of Science in Chemistry in Mapúa University, Manila, Philippines. The author is highly interested in research activities related to natural products and pharmacology.

Kathlia Aguila De Castro-Cruz is a full-time Professor in the School of Chemical, Biological, and Materials Engineering, and Sciences, Mapúa University, Manila, Philippines. The author is highly interested in research activities related to organic total synthesis, isolation and structural elucidation of natural products.

Chieh-Lun Hsieh is a Ph.D. Student in Educational Management Major in P.E., Graduate School, Emilio Aguinaldo College, Manila, Philippines. The author is highly interested in research activities related to sport medicine in natural products.

Po-Wei Tsai is working as an Associate Professor in the Department of Medical Sciences Industry, College of Health Sciences, Chang Jung Christian University, Tainan, Taiwan. Author's area of interest is research activities in phytochemistry, antioxidant, anti-osteoarthritis in natural products.

Cite this article: Barbaza MYU, Castro-Cruz KAD, Hsieh C, Tsai P. Determination of the Chemical Constituent Contents and Antioxidation Properties of Asystasia Gangetica. Indian J of Pharmaceutical Education and Research. $2021 ; 55(3): 863-71$. 